\title{
Correction
}

\section{Correction: Darbelli et al., “Quaking Regulates Neurofascin 155 Expression for Myelin and Axoglial Junction Maintenance"}

In the article "Quaking Regulates Neurofascin 155 Expression for Myelin and Axoglial Junction Maintenance" by Lama Darbelli, Gillian Vogel, Guillermina Almazan, and Stéphane Richard, which appeared on pages 4106-4120 of the April 6, 2016 issue, an incorrect image of a peripheral nerve, which could represent a cranial nerve like oculomotorius or trochlearis, was inadvertently shown. (Fig. 3C). The correct image should be as shown below. We have recalculated the g-ratio for optic nerve QKIFL/FL; ${ }^{-}$(Fig. 3G) and updated the figure (same axon count was used, $n=108$ ).
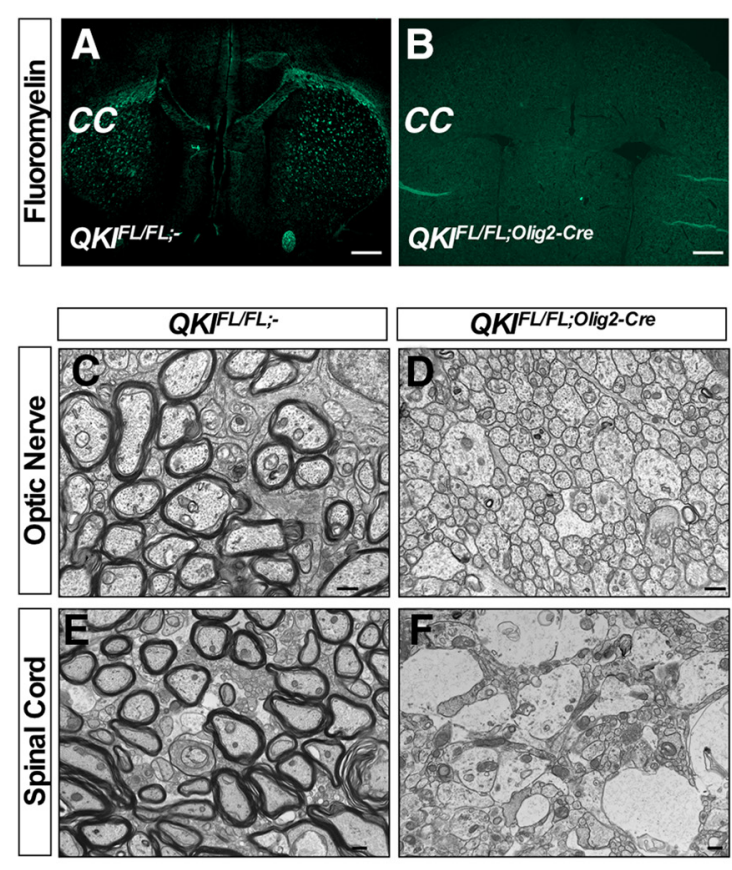
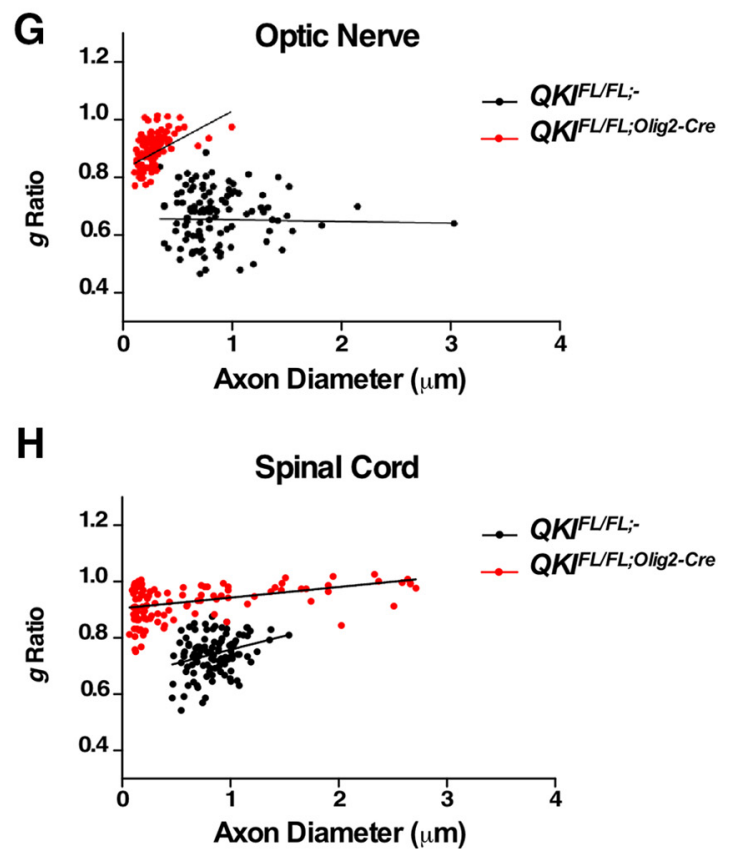

Figure 3. 